\title{
Impact of Fruit and Vegetables on Oxidative Status and Lipid Profiles in Healthy Individuals
}

\author{
Sapwarobol Suwimol ${ }^{1, *}$, Luangcharoenkul Pimpanit ${ }^{2}$, Metavee Aporn ${ }^{2}$, Singlaw Pichita ${ }^{2}$, Seawsiri \\ Ratiyaporn $^{2}$, Jiamjarasrangsi Wiroj ${ }^{3}$ \\ ${ }^{1}$ Nutrition and Dietetics Program, Faculty of Allied Health Science, Chulalongkorn University, Bangkok 10330, Thailand \\ ${ }^{2}$ Undergraduate Program in Nutrition and Dietetics, Faculty of Allied Health Sciences, Chulalongkorn University, Bangkok 10330, \\ Thailand \\ ${ }^{3}$ Department of Preventive and Social Medicine, Faculty of Medicine, Chulalongkorn University, Bangkok 10330, Thailand
}

\begin{abstract}
This study aims to investigate the effect of different amount of low, medium and high (3, 5 and 8 servings/day) fruit and vegetables $(\mathrm{F}+\mathrm{V})$ consumption on blood lipid profile and plasma malondialdehyde (MDA) in healthy individuals. In a parallel trial, 63 subjects were randomly assigned into one of the three different dietary interventions. Anthropometric, blood lipid profile and MDA were evaluated at baseline and after 4 weeks intervention. The results showed that consumption of $\mathrm{F}+\mathrm{V} 5$ and 8 servings/d could significantly reduce low density lipoprotein (LDL-C) concentrations with a mean difference $(95 \% \mathrm{CI})$ of $-13.28,(-4.00,-22.55)$ and $-9.31(-2.25,-16.38) \mathrm{mg} / \mathrm{dL}$ respectively. In addition, 8 servings $/ \mathrm{d}$ of $\mathrm{F}+\mathrm{V}$ consumption had shown to significantly reduced plasma MDA concentrations with a mean difference $(95 \% \mathrm{CI})$ of -0.15 $(-0.09,-0.2) \mathrm{mg} / \mathrm{dL}$, and $p$-value $<0.05$. Therefore, consumption of 8 servings $\mathrm{F}+\mathrm{V}$ daily pose health benefits on both reducing LDL-C concentrations and improving oxidative status.
\end{abstract}

Keywords Blood Lipid Profiles, Oxidative Status, Fruits and Vegetables

\section{Introduction}

The protective role of regular consumption of fruit and vegetables $(\mathrm{F}+\mathrm{V})$ against several chronic diseases such as coronary heart disease[1-4], cancer[5], diabetes mellitus[6], and diverticulitis[7] has been established. In light of the evidence linking fruit and vegetables intake and chronic diseases mentioned, vitamin $\mathrm{C}$, beta-carotene, vitamin $\mathrm{E}$ and phytonutrients contained in $\mathrm{F}+\mathrm{V}$ have been shown a protective health benefit by decreasing malondialdehyde (MDA) level leading to a reduction of inflammatory-related diseases risk[8-10]. In addition, a soluble fiber in diet rich in $\mathrm{F}+\mathrm{V}$ may assist to optimize serum cholesterol level, a well-known risk factor for cardiovascular disease[11]. The World Health Organization (WHO) therefore recommends that a minimum of $400 \mathrm{~g}$ or 5 servings of $\mathrm{F}+\mathrm{V}$ should be consumed daily in order to obtain health benefits[7]. All nations have been called to establish campaigns to increase fruit and vegetables consumption to meet the WHO recommendations. In respond to WHO recommendations, The Ministry of Public Health of Thailand recommends a minimum of 5 servings or $400 \mathrm{~g}$ of $\mathrm{F}+\mathrm{V}$ each day.

\footnotetext{
* Corresponding author:

suwimol.sa@chula.ac.th (Sapwarobol Suwimol)

Published online at http://journal.sapub.org/fph

Copyright (C) 2012 Scientific \& Academic Publishing. All Rights Reserved
}

Even though the recommendation has been widely promoted, an average $\mathrm{F}+\mathrm{V}$ consumption in Thai population remains very low compare to the recommendation. The 2003 Thai Health Survey revealed the average $\mathrm{F}+\mathrm{V}$ consumption in Thai population to be only 268 and $283 \mathrm{~g}$ /day in adult males and females, respectively[12].

The objective of this study was to investigate the effects of different amounts of $\mathrm{F}+\mathrm{V}$ intake: low (3 servings/day), medium (5 servings/day) and high ( 8 servings/day) on blood lipid profile and a marker of oxidative stress among healthy individuals.

\section{Methods}

\section{Subjects}

Eighty- four healthy individuals aged 18-30 were recruited for the study through advertisements posted at Chulalongkorn University and a nearby community. All participants were in apparent good health as evaluated by medical history, physical examination and screening history. The eligibility criteria included (1) normal serum cholesterol level (less than $200 \mathrm{mg} / \mathrm{dL}$ ) (2) not receiving medications or dietary supplements known to alter antioxidant levels; (3) no clinical history of cardiovascular, diabetes mellitus, hypertension or inflammatory diseases; (4) no alcohol intake; (5) no recent history of smoking. (6) no known dietary restrictions/food allergies. Eighty-four subjected were recruited to the study. Fourteen subjects 
reported antioxidant-related supplement used. Seven subjects dropped out because of personal reasons. Sixty-three subjects fulfilled the inclusion criteria and completed the study. (Figure 1).

The study protocol was approved by the Ethical Review Committee for Research Involving Human Research Participants, Health Science Group, Chulalongkorn University. Written informed consent was obtained from all subjects prior to enrolling to the study. Subject's anonymity was preserved.

\section{Study design}

This trial was a nutritional intervention controlled by registered dietitian from the Department of Nutrition and Dietetics of the Chulalongkorn University. The study was a randomized parallel trial of 4-weeks intervention with a 2 -week run-in period. During run-in period, all subjects were assigned to consume 3 servings/d of $\mathrm{F}+\mathrm{V}$ to diminish the impact of background diet on study outcomes. After a 2-week run-in period, a group of 63 subjects were then randomly assigned into one of the three dietary intervention groups; low ( 3 servings/day), medium ( 5 servings/day) and high ( 8 servings/day) $\mathrm{F}+\mathrm{V}$ intake.

\section{Dietary treatment}

Subjects were requested to consume $\mathrm{F}+\mathrm{V}$ according to their assigned amounts of a low (3 servings/day), medium (5 servings/day) and high ( 8 servings/day) for four weeks (Figure 1). The energy requirements of the subject were estimated on the basis of body weight, age, and physical activity. Macronutrients composition including carbohydrate, protein and fat was kept similar among the three intervention groups. Registered dietician coached all subjects on $\mathrm{F}+\mathrm{V}$ serving size to ensure the amounts consumed. Food model was utilized to guarantee serving size understanding. Subjects were allowed to consume $\mathrm{F}+\mathrm{V}$ according to their cooking preferences. $\mathrm{F}+\mathrm{V}$ are recommended to eat fresh if possible. In order to evaluate and monitor the subject's compliance, all subjects were requested to record the $\mathrm{F}+\mathrm{V}$ consumed at least 2 days a week, including 1 weekday and 1 weekend day throughout the study. Structured interviews were also utilized through at least 2 telephone calls per week. Beside $\mathrm{F}+\mathrm{V}$ intake, all subjects were requested to keep their lifestyles and exercise habit unchanged throughout the study.

\section{Anthropometrics assessment}

Weight, Body Mass Index (BMI), and percent body fat were measured at baseline (week-0) and the end of treatment period (week-4). Body weight, and percent body fat mass were assessed using a constant current source with a high frequency current $(50 \mathrm{kHz}, 500 \mu \mathrm{A})$-bioelectrical impedance analyzer (BIA) (BC-418 body composition analyzer, TANITA corporation, Tokyo, JAPAN). The subject was requested to dress in light attire and bare feet. The 8 polar electrodes were positioned so that electric current was supplied from the electrodes on the tips of the toes of both feet and the fingertips of both hands, and voltage is measured on the heel of both feet and the thenar side of both hands. Body Mass Index (BMI) was calculated as weight/height ${ }^{2}$ (in kilograms per square meter).

\section{Blood analysis}

Fasting blood samples were also collected at baseline and the end of treatment period and were analyzed in a blind fashion. At the beginning (baseline) and at the end of the treatment period (week 4), $9 \mathrm{ml}$ of overnight fasting venous blood samples was collected from all subjects. Blood was collected in tubes that contained lithium heparin. Plasma was collected after centrifugation at $1500 \mathrm{x}$ g for $10 \mathrm{~min}$ at 4 degree C. Plasma MDA concentrations were analyzed by spectrophotometer, according to the method of Moore and Robert, 1998[13]. Plasma was mixed with $10 \%$ trichloroacetic acid (TCA), then centrifuged at 8000x g for $10 \mathrm{~min}$. A 2-Thiobarbituric acid (TBA) was then added to the aliquots. The supernatant fluid was heated at 95 degree $C$ for $10 \mathrm{~min}$ before measuring absorbance by spectrophotometer at $532 \mathrm{~nm}$. Lipid profiles analysis was performed at baseline and after 4-weeks of the study. All of the anti-oxidation capacity and blood lipid profiles analysis have been done at the Nutrition laboratory, Faculty of Allied Health Science, Chulalongkorn University.

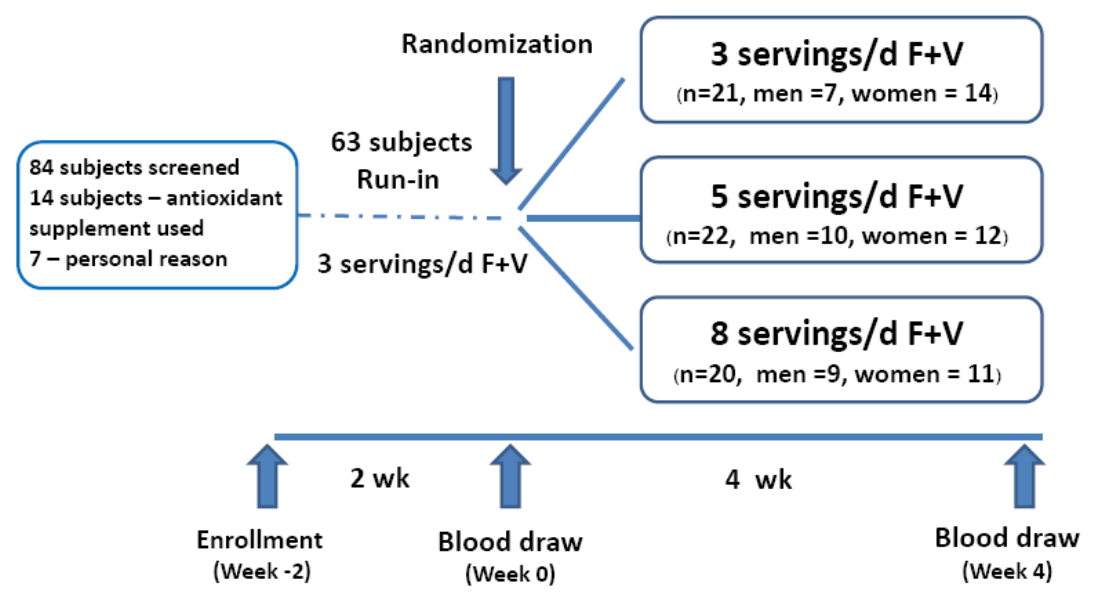

Figure 1. Study design 


\section{Statistical analysis}

Results are reported as means \pm standard deviation (SDs). To assess the effectiveness of randomization, the differences between the groups at baseline were analyzed using analysis of variance (ANOVA). In the evaluation of the intervention effectiveness, the independent variable was number of servings of $\mathrm{F}+\mathrm{V}$ ( 3,5 or 8 servings/d), and the primary endpoints were changes in lipid profiles and MDA concentrations between baseline and week 4 . We used analysis of variance containing 2 time points and 3 groups to analyze the data. Paired t-test was also utilized in evaluating the significance of these changes within each intervention groups. Values of $\mathrm{P}<0.05$ were considered significant. All statistical analyses were performed with the SPSS )Statistical Package for Social Science version 17.0, SPSS Inc, Chicago, IL).

\section{Results and Discussion}

Sixty-three subjects completed the study with full compliance. Subjects were randomly assigned into one of the three groups; low ( 3 servings/day), medium ( 5 servings/day) and high (8 servings/day) $\mathrm{F}+\mathrm{V}$. Group of $\mathrm{F}+\mathrm{V} 3,5$ and 8 servings/day consists of 21 ( 7 men, 14 women, age $20 \pm 1.24$ years, BMI $\left.20.32 \pm 1.67 \mathrm{~kg} / \mathrm{m}^{2}\right), 22(10 \mathrm{men}, 12$ women, age $21 \pm 0.97$ years, BMI $\left.20.59 \pm 1.54 \mathrm{~kg} / \mathrm{m}^{2}\right)$, and $20(9$ men, 11 women, age $20 \pm 1.79$ years, BMI $\left.20.48 \pm 2.06 \mathrm{~kg} / \mathrm{m}^{2}\right)$ subjects respectively. Baseline (week-0) characteristics of each groups including age, body weight, BMI, percent body fat, total cholesterol, LDL-C, HDL-C, triglyceride, cholesterol/HDL-C index, triglyceride/HDL-C index and plasma MDA are shown in Table 1. There were no significant differences on these baseline characteristics (Table 1).

Table 1. Baseline characteristics, habitual daily dietary intake, blood lipid profiles and plasma MDA in the 3 groups

\begin{tabular}{|c|c|c|c|}
\hline & \multicolumn{3}{|c|}{ No. of servings/d } \\
\hline & $\begin{array}{c}3 \\
(\mathrm{n}=21, \text { men }=7, \text { women }= \\
14)\end{array}$ & $\begin{array}{c}5 \\
(\mathrm{n}=22, \text { men }=10, \text { women }= \\
12)\end{array}$ & $\begin{array}{c}8 \\
(\mathrm{n}=20, \text { men }=9, \text { women }= \\
11)\end{array}$ \\
\hline Age (y) & $20 \pm 1.24$ & $21 \pm 0.97$ & $20 \pm 1.79$ \\
\hline BMI (kg/m2) & $20.32 \pm 1.67$ & $20.59 \pm 1.54$ & $20.48 \pm 2.06$ \\
\hline Weight (kg) & $53.64 \pm 7.66$ & $56.79 \pm 6.95$ & $56.02 \pm 7.77$ \\
\hline Percent body fat (\%) & $22.41 \pm 5.78$ & $21.35 \pm 6.79$ & $20.77 \pm 8.49$ \\
\hline Cholesterol (mg/dL) & $197.63 \pm 7.32$ & $188.50 \pm 6.88$ & $174.70 \pm 6.17$ \\
\hline Triglyceride (mg/dL) & $64.75 \pm 4.67$ & $66.47 \pm 7.53$ & $58.64 \pm 5.69$ \\
\hline HDL-C (mg/dL) & $52.12 \pm 2.68$ & $53.50 \pm 2.34$ & $55.37 \pm 2.40$ \\
\hline LDL-C (mg/dL) & $132.89 \pm 6.42$ & $132.64 \pm 7.86$ & $122.41 \pm 6.16$ \\
\hline Cholesterol/HDL-C index & $4.13 \pm 0.88$ & $3.69 \pm 0.91$ & $3.23 \pm 0.57$ \\
\hline Triglyceride/HDL-C index & $1.24 \pm 0.46$ & $1.31 \pm 0.76$ & $1.12 \pm 0.58$ \\
\hline $\operatorname{MDA}(\mu \mathrm{mol} / \mathrm{L})$ & $0.66 \pm 0.03$ & $0.89 \pm 0.04$ & $0.76 \pm 0.05$ \\
\hline
\end{tabular}

All values are mean \pm SD. There were no significant differences observed among three groups at baseline

Table 2. Average number of servings of fruit and vegetables consumed daily during week $-2-0$ (run-in period) and week $0-4$ (intervention period)

\begin{tabular}{|c|c|c|c|}
\hline & \multicolumn{3}{|c|}{ No. of servings/d } \\
\hline & $\begin{array}{c}3 \\
(\mathrm{n}=21, \text { men }=7, \text { women }= \\
14)\end{array}$ & $\begin{array}{c}5 \\
(\mathrm{n}=22, \text { men }=10, \text { women } \\
=12)\end{array}$ & $\begin{array}{c}8 \\
(\mathrm{n}=20, \text { men }=9, \text { women }= \\
11)\end{array}$ \\
\hline \multicolumn{4}{|c|}{ Run-in period (week -2 -0) } \\
\hline Fruit & $1.2 \pm 0.3$ & $1.3 \pm 0.4$ & $1.7 \pm 0.2$ \\
\hline Vegetables & $1.6 \pm 0.2$ & $1.3 \pm 0.3$ & $1.9 \pm 0.3$ \\
\hline Total & $2.8 \pm 0.5$ & $2.6 \pm 0.6$ & $3.6 \pm 0.4$ \\
\hline \multicolumn{4}{|c|}{ Intervention period (week $0-4$ ) } \\
\hline Fruit & $1.4 \pm 0.5$ & $2.3 \pm 0.1$ & $3.5 \pm 0.3$ \\
\hline Vegetables & $1.7 \pm 0.2$ & $2.5 \pm 0.2$ & $4.3 \pm 0.2$ \\
\hline Total & $3.1 \pm 0.7$ & $4.8 \pm 0.3$ & $7.8 \pm 0.5$ \\
\hline
\end{tabular}

All values are mean \pm SD. Values were calculated with a dietary record. All groups were instructed to consumed 3 servings/d during weeks $-2-0$ 
Table 3. Body weight, BMI and percent body fat in subjects consumed 3,5 or 8 servings/d of fruit and vegetables at baseline and after 4 weeks intervention

\begin{tabular}{|c|c|c|c|c|c|c|}
\hline & \multicolumn{6}{|c|}{ No. of servings/d } \\
\hline & \multicolumn{2}{|l|}{3} & \multicolumn{2}{|l|}{5} & \multicolumn{2}{|l|}{8} \\
\hline & Mean $\pm \mathrm{SD}$ & p-value & Mean \pm SD & p-value & Mean $\pm \mathrm{SD}$ & p-value \\
\hline \multicolumn{7}{|c|}{ Body weight (kg) } \\
\hline baseline & $53.64 \pm 7.66$ & 0.62 & $56.79 \pm 6.95$ & 0.45 & $56.02 \pm 7.77$ & 0.54 \\
\hline intervention & $53.43 \pm 7.86$ & & $57.07 \pm 7.03$ & & $56.10 \pm 8.05$ & \\
\hline \multicolumn{7}{|c|}{ BMI (kg/m2) } \\
\hline baseline & $20.32 \pm 1.67$ & 0.64 & $20.59 \pm 1.54$ & 0.56 & $20.48 \pm 2.06$ & 0.48 \\
\hline intervention & $20.15 \pm 1.20$ & & $20.46 \pm 1.02$ & & $20.57 \pm 1.86$ & \\
\hline \multicolumn{7}{|c|}{ Percent body fat (\%) } \\
\hline baseline & $22.41 \pm 5.78$ & 0.65 & $21.35 \pm 6.79$ & 0.46 & $20.77 \pm 8.49$ & 0.42 \\
\hline intervention & $22.15 \pm 6.19$ & & $21.39 \pm 6.77$ & & $20.88 \pm 8.49$ & \\
\hline
\end{tabular}

All values are mean \pm SD. No significant difference observed after 4 -week dietary intervention

Table 4. Mean difference ( $95 \%$ CI) of lipid profiles, total cholesterol, triglyceride, HDL-C, LDL-C, cholesterol/HDL-C index, Triglyceride/HDL-C index and MDA in subjects who consumed 3, 5 or 8 servings/d of fruit and vegetables for 4 week (week $0-4$ )

\begin{tabular}{|c|c|c|c|c|c|c|}
\hline & \multicolumn{6}{|c|}{ No. of servings/d } \\
\hline & $\begin{array}{c}3 \\
\text { Mean } \\
\text { Difference }(95 \% \mathrm{CI}) \\
\end{array}$ & p-Value & $\begin{array}{c}5 \\
\text { Mean } \\
\text { Difference }(95 \% \mathrm{CI}) \\
\end{array}$ & p-Value & $\begin{array}{c}8 \\
\text { Mean Difference }(95 \% \mathrm{CI})\end{array}$ & P-Value \\
\hline $\begin{array}{c}\text { Total } \\
\text { Cholesterol(mg/dL) } \\
\end{array}$ & $0.94(-7.36,9.24)$ & 0.81 & $-5.50(-15.66,4.66)$ & 0.27 & $-4.65(-12.40,3.11)$ & 0.22 \\
\hline Triglyceride(mg/dL) & $-4.20(-9.51,1.11)$ & 0.11 & $-5.60(-15.73,4.53)$ & 0.26 & $-1.93(-7.97,4.12)$ & 0.50 \\
\hline HDL-C (mg/dL) & $-0.29(-3.97,3.38)$ & 0.87 & $-1.55(-4.39,1.30)$ & 0.27 & $-2.21(-5.65,1.23)$ & 0.19 \\
\hline LDL-C (mg/dL) & $-5.44(-13.02,2.15)$ & 0.15 & $-13.28(-22.55,-4.00)$ & $<0.05^{*}$ & $-9.31(-16.38,-2.25)$ & $<0.05^{*}$ \\
\hline $\begin{array}{l}\begin{array}{c}\text { Cholesterol/ HDL-C } \\
\text { index }\end{array} \\
\end{array}$ & $-0.19(-0.59,0.22)$ & 0.34 & $0.05(-0.29,0.40)$ & 0.76 & $0.12(-0.22,0.45)$ & 0.47 \\
\hline $\begin{array}{c}\text { Triglyceride/HDL-C } \\
\text { index } \\
\end{array}$ & $-0.05(-0.21,0.10)$ & 0.48 & $-0.07(-0.25,0.12)$ & 0.45 & $-0.01(-0.20,0.17)$ & 0.87 \\
\hline $\operatorname{MDA}(\mu \mathrm{mol} / \mathrm{L})$ & $-0.03(-0.11,0.04)$ & 0.38 & $-0.05(-0.11,0.01)$ & 0.08 & $-0.15(-0.2,-0.09)$ & $<0.05^{*}$ \\
\hline
\end{tabular}

* significant different from week $-0, p<0.05$

Compliance to the $\mathrm{F}+\mathrm{V}$ consumption was inferred from the telephone calls and dietary records (1 weekday and 1 weekend day). The numbers of servings of $\mathrm{F}+\mathrm{V}$ consumed at baseline and during the 4-week intervention period are presented in Table 2, which confirmed compliance of the subjects. After the course of this 4 week F+V intervention, body weight, percent body fat and BMI did not change significantly in every group (Table 3). Blood lipid profiles including total cholesterol, triglyceride, HDL-C, cholesterol/HDL-C index and triglyceride/HDL-C index were not significantly different after 4-week of $\mathrm{F}+\mathrm{V}$ intervention in every groups. However, significant reduction in LDL-C concentrations were observed in the groups consumed 5 and 8 servings/d (mean difference $(95 \% \mathrm{CI}$ ) $-13.28,(-4.00,-22.55)$ and $-9.31(-2.25,-16.38) \mathrm{mg} / \mathrm{dL}$ respectively) (Table 4).
No significant different in the concentration of plasma MDA was observed in the groups of 3 and 5 servings/d however, only the group consumed 8 servings/d of F+V had been shown to significantly reduced plasma MDA concentrations with a mean difference $(95 \% \mathrm{CI})$ of $-0.15(-0.09,-0.2) \mathrm{mg} / \mathrm{dL}$, with $p$-value $<0.05$ (Table 4).

In present study, $\mathrm{F}+\mathrm{V}$ consumption in a minimum of 5 servings/d reduced LDL-C concentrations in healthy young adults. The present results confirmed with those obtained from previous studies that $\mathrm{F}+\mathrm{V}$ intake resulted in a marked reduction in lipid risk factors for cardiovascular disease. In a parallel, single-blind fashion, administration of $\mathrm{F}+\mathrm{V}$ for 12 weeks decreased total cholesterol concentration by $7.3 \%[14]$. Similarly, in a randomized crossover design study, a diet consisting of low-calorie vegetables, fruit and nuts had been demonstrated to reduce LDL-C level by $33 \%[15]$. The 
beneficial effect of $\mathrm{F}+\mathrm{V}$ ingestion may associate with the assorted range of biologically active components and fibers contained in plant foods. Soluble fiber in plants had been shown to decrease serum cholesterol[16].

Several propose mechanisms by which dietary fiber reduce blood cholesterol has been established. Study reported that soluble fiber bind bile acids or cholesterol during micelles formation resulting in lower cholesterol content of liver cells and leads to upregulating of LDL receptors and increase LDL clearance[17].

Eight servings/d of $\mathrm{F}+\mathrm{V}$ consumption was shown to improve oxidative status by reducing MDA concentrations. MDA is an indicator of lipid peroxidation since it is an end product of oxidative process. $\mathrm{F}+\mathrm{V}$ contain antioxidant vitamins and phytochemicals, which could result in the scavenging of reactive oxygen species produced during lipid peroxidation. Study reported that $\mathrm{F}+\mathrm{V}$ consumption improved antioxidant status by improving plasma total antioxidant capacity and glutathione peroxidase activity in healthy young adults[18]. In accordance with our observation, an improvement of oxidative status was established after 8 servings of $\mathrm{F}+\mathrm{V}$ ingestion in young adults[19]. In addition, well-controlled dietary studies have also reported the beneficial effect of 5 servings of $\mathrm{F}+\mathrm{V}$ or more on markers of inflammation and oxidative stress [20-21].

\section{Conclusions}

The outcome of this nutritional trial shows that $\mathrm{F}+\mathrm{V}$ consumption at least 5 serving/d appears to be effective in improving blood lipid profiles in young healthy adults. The supply of antioxidant components naturally found in $\mathrm{F}+\mathrm{V}$ could be benefit in improving oxidative status as well. Therefore, including $\mathrm{F}+\mathrm{V}$ in a minimum of 8 servings/d in a habitual diet may pose health benefit on both reducing LDL-C concentrations and improving oxidative status.

\section{ACKNOWLEDGEMENTS}

This work was supported by staffs at Nutrition laboratory, Faculty of Allied Health Science, Chulalongkorn University. We are grateful for a very helpful of all participants in this project.

\section{REFERENCES}

[1] L. Dauchet, P. Amouyel, J. Dallongeville, Fruit and vegetable consumption and risk of coronary heart disease: a meta-analysis of cohort studies. J Nutr 136, 2588-93, 2006.

[2] P. Knekt, A. Reunanen, R. Jarvinen, R. Seppanen, M. Heliovaara, A. Aromma, Antioxidant vitamin intake and coronary mortality in a longitudinal population study. Am J
Epidemiol 139, 1180-9, 1994.

[3] M. R. Law, J. K. Morris, By how much does fruit and vegetable consumption reduce risk of ischemic heart disease? Eur J Clin Nutr 52, 549-56, 1998.

[4] S. Sasazuki, Case-control study of nonfatal myocardial infraction in relation to selected foods in Japanese men and women. Jpn Circ J 65, 200-6, 2001.

[5] The World Cancer Research Fund and American Institue for Cancer Research. Food and Nutrition, Physical Activity and the Prevention of Cancer: A Global Perspective. Washington, DC: ACIR, 2007.

[6] E. S. Ford, A. H. Mokdad, Fruit and vegetable consumption and diabetes millitus incidence among US adults. Prev Med $32,33-9,2001$.

[7] FAO/WHO. Diet, Nutrition and the Prevention of Chronic Diseases. Report of A joint FAO/WHO Expert Consultation. Geneva: World Health Organization, 2003.

[8] S. O. Keli, M. G. L. Hertog, E. J. M. Feskens, D. Kromhout, Dietary flavonoids, antioxidant vitamins and incidence of stroke: the Zutphen Study. Arch Intern Med 154, 637-642, 1996.

[9] M. G. L. Hertog, E. J. M. Feskens, P. C. H. Hollman, M. B. Katan, D. Kromhout, Dietary antioxidant flavonoids and risk of coronary heart disease: the Zutphen Elderly Study. Lancet 342, 1007-1011, 1993.

[10] K. A. Steinmetz, J. D. Potter, Vegetables, fruit and cancer prevention: a review. J Am Diet Assoc 96, 1027-1039,1996.

[11] M. Klerk, M. C. J. F. Jansen, P. Van't Veer, F. J. Kok, Fruit and vegetables in chronic disease prevention. Wageningen, The Netherlands: Grafisch Bedrijf Ponsen\&Looijen BV. 1998.

[12] The $3^{\text {rd }}$ health status surveys in Thai population, Health Information System Development Office, Ministry of Public Health; 2003. Available at www.hiso.or.th/hiso/HealthRe port/report2546-2547.php, Cited: July 22, 2011.

[13] K. Moore, L. J. Roberts. Measurement of lipid peroxidation, Free Radic Res 2, 659-671, 1998.

[14] R. B. Singh, S. S. Rastogi, Effect of fat-modified and fruitand vegetable-enriched diets on blood lipids in the Indian diet heart study. Am J Cardiol 70(9), 869-874, 1992.

[15] D. J. A. Jenkins, D. G Popovich, Effect of a diet high in vegetables, fruit, and nuts on serum lipids. Metabolism 46(5), 530-537, 1997.

[16] J. W. Anderson, T. F. Garrity, C. L. Wood, Prospective, randomized, controlled comparison of the effects of low-fat and low-fat plus high-fiber diets on serum lipid concentrations. AM J Clin Nutr 56, 887-84, 1992.

[17] R. Aller, D. A. de Luis, O. Izaola, F. La Calle, L. del Olmo, L. Fernandez, Effect of soluble fiber intake in lipid and glucose levels in healthy subjects: a randomized clinical trail. Diabetes Res Ckin Pract 65, 7-11, 2004.

[18] H. H. M. Hermsdorff, K. B. F. Barbosa, A. C. P. Volp, B. Pachau, J. Bressan, M. A. Zulet, J. A. Martinez, Vitamin C and fibre consumption from fruits and vegetables improves oxidative stress markers in healthy young adults. Br J Nutr 7, $1-9,2011$. 
[19] A. Olivereira, F. Rodriguez-Artalejo, C. Lopes, The association of fruits, vegetables, antioxidant vitamins and fibre intake with high-sensitivity C-reactive protein: sex and body mass index interactions. Eur J Clin Nutr 63, 1345-1352, 2009.

[20] H. J. Thompson, J. Heimendinger, A. Haegele, Effects of increased vegetable and fruit consumption on markers of oxidative cellular damage. Carcinogenesis 20, 2261-6, 1999.

[21] E. M. Holt, L. M. Steffen, Fruit and Vegetable Consumption and Its Relation to Markers of Inflammation and Oxidative Stress in Adolescents. J Am Diet Assoc 109(3), 414-421, 2009. 